\title{
Effect of quercetin on the proliferation of the human ovarian cancer cell line SKOV-3 in vitro
}

\author{
MING-XIN REN ${ }^{1}$, XIAO-HUI DENG ${ }^{1}$, FANG AI $^{2}$, GUO-YAN YUAN ${ }^{2}$ and HAI-YAN SONG ${ }^{1}$ \\ ${ }^{1}$ Department of Human Anatomy, Xinxiang Medical University, Xinxiang, Henan 453003; \\ ${ }^{2}$ Department of Neurosurgery, First Affiliated Hospital of Xinxiang Medical University, Weihui, Henan 453000, P.R. China
}

Received May 19, 2014; Accepted January 20, 2015

DOI: $10.3892 / \mathrm{etm} .2015 .2536$

\begin{abstract}
Quercetin is a hydrophobic agent that demonstrates potential anticancer activity. The aim of the present study was to observe the effects of quercetin on the proliferation and apoptosis of the ovarian cancer cell line SKOV-3, and to provide a foundation for the treatment of ovarian cancer using this agent. Ovarian cancer SKOV-3 cells were treated with quercetin at different doses. The inhibitory effect of quercetin on proliferation was detected using the MTT assay and the inhibition rate was calculated. Cell apoptosis was determined using Hoechst staining, and western blot analysis was used to analyze changes in the expression levels of survivin protein. The effects of quercetin on the cell cycle and apoptosis of the SKOV-3 cell line were analyzed using flow cytometry. Quercetin inhibited the proliferation of SKOV-3 cells in a time- and dose-dependent manner. Furthermore, Hoechst staining showed that quercetin induced SKOV-3 cell apoptosis. The protein expression levels of survivin were reduced as the concentration of quercetin increased. Flow cytometric analysis showed that quercetin caused ovarian cancer SKOV-3 cell cycle arrest in the $\mathrm{G}_{0} / \mathrm{G}_{1}$ phase and a significant decrease in the percentage of cells at the $\mathrm{G}_{2} / \mathrm{M}$ phase; furthermore, the apoptosis rate was observed to increase following quercetin treatment. The results in combination indicated that Quercetin could inhibit the proliferation of ovarian cancer SKOV-3 cells, inhibit cell cycle progression from $G_{0} / G_{1}$ to $G_{2} / M$ and induce cell apoptosis in vitro.
\end{abstract}

\section{Introduction}

Ovarian cancer is the third most common female genaital malignancy behind cervical and uterine cancer. ; however, ovarian cancer has the highest mortality rate of all the

Correspondence to: Mrs. Xiao-Hui Deng, Department of Human Anatomy, Xinxiang Medical University, 601 Jinsui Road, Xinxiang, Henan 453003, P.R. China

E-mail: dengxhhappy@126.com

Key words: apoptosis, proliferation, survivin, ovarian cancer, quercetin gynecologic cancers (1), posing a serious threat to the health of females. Furthermore, in the United States, there are 21880 cases of ovarian cancer diagnosed annually, and $\sim 13,850$ patients succumb to ovarian cancer each year (2). At present, chemotherapeutic agents used for the treatment of ovarian cancer can not only kill the tumor cells, but also damage the normal cells; therefore, there is an urgent requirement for the development of effective chemotherapy drugs for ovarian cancer (3).

Quercetin, a flavonoid, is widespread in nature and can be found in fruits, vegetables and plants $(4,5)$. Quercetin has been demonstrated to be able to inhibit the growth of tumor cells, prevent cancer metastasis and suppress cancer cell proliferation by inducing tumor cell apoptosis or cell cycle arrest at a certain stage within the cycle, suggesting that the compound has potential for use in the treatment of cancer (6-8). Our preliminary unpublished data suggest that quercetin has inhibitory effects on gastric and esophageal cancer; however, the effects of quercetin on ovarian cancer require further study. The aim of the present study was therefore to observe the effects of quercetin on the proliferation and apoptosis of the ovarian cancer cell line SKOV-3 in vitro, and to provide a foundation for the treatment of ovarian cancer using this agent.

\section{Materials and methods}

Materials. The human ovarian cancer cell line SKOV-3 was obtained from the Tumor Cell Library of the Chinese Academy of Medical Sciences (Beijing, China). Quercetin (Sigma, St. Louis, MO, USA) was suspended in dimethylsulfoxide (DMSO; Sigma) and stored at $-20^{\circ} \mathrm{C}$. MTT was purchased from Sigma. Dulbecco's modified Eagle's medium (DMEM), fetal calf serum (FCS) and TRIzol ${ }^{\mathrm{TM}}$ reagent were purchased from Invitrogen Life Technologies (Carlsbad, CA, USA), and Hoechst 33258 was provided by Biyuntian Biotechnology Research Institute (Haimen, China).

\section{Methods}

Cell culture. Human ovarian cancer SKOV-3 cells were cultured in $10 \%$ DMEM containing $10 \% \mathrm{FCS}$ at $37^{\circ} \mathrm{C}$ under saturated humidity conditions in $5 \% \mathrm{CO}_{2}$. The medium was replaced every two or three days.

Cell viability and proliferation. The SKOV-3 cells were harvested during the logarithmic growth phase and digested 
with trypsin. The effects of quercetin on SKOV-3 cell proliferation and viability were investigated by plating the SKOV-3 cells $\left(5 \times 10^{3} /\right.$ well $)$ in 96 -well plates and incubating the cells in DMEM supplemented with $10 \%$ FCS. After $24 \mathrm{~h}$, the cells were washed once with medium and treated with $0,0.12,0.23$, $0.47,0.94,1.88,3.75,7.5,15$ or $30 \mathrm{mg} / \mathrm{ml}$ quercetin added to the medium. The control wells contained SKOV-3 cells cultured without the addition of quercetin, and blank wells containing only culture medium were established. Cell proliferation and viability were assessed after 24 or $48 \mathrm{~h}$ of treatment by incubating the cells in DMEM supplemented with 10\% FCS and $20 \mu \mathrm{l} \mathrm{MTT}(5 \mathrm{mg} / \mathrm{ml})$ for $4 \mathrm{~h}$. Following the swilling of the culture solution, $150 \mu 1$ DMSO was added to each well and the solution was agitated to completely dissolve the blue-purple precipitate obtained from the MTT. A microplate reader (OPTImax; Molecular Dynamics, Sunnyvale, CA, USA) was used to measure the absorbance of each well at $540 \mathrm{~nm}$ and the average values were obtained. The experiments were repeated at least three times, and data are presented as the mean \pm standard deviation (SD).

Cell apoptosis analysis. The SKOV-3 cells were double-stained with Annexin V-fluorescein isothiocyanate (FITC) and propidium iodide (PI), and cell apoptosis was then analyzed using flow cytometry (FCM) with an inverted fluorescence microscope (Axiovert 200; Carl Zeiss SMT GmbH, Oberkochen, Germany). In brief, the adherent cells treated with quercetin at different concentrations $(0,15$ or $30 \mathrm{mg} / \mathrm{ml})$ for $24 \mathrm{~h}$ were collected in a centrifuge tube, and the cell density was adjusted to $1 \times 10^{6} / \mathrm{ml}$. Following centrifugation at $700 \mathrm{x} \mathrm{g}$ at $4^{\circ} \mathrm{C}$ for $5 \mathrm{~min}$, the supernatant was discarded and the pelleted cells were collected and washed with phosphate-buffered saline (PBS), prior to further centrifugation. The cells were then resuspended in $200 \mu \mathrm{l}$ incubation buffer, $10 \mu \mathrm{l}$ Annexin V-FITC/PI was added and the cells were incubated for $15 \mathrm{~min}$ at room temperature away from the light. Following incubation, $300 \mu \mathrm{l}$ incubation buffer was added to the cells and the samples were analyzed for cell apoptosis using a BD FACSCalibur ${ }^{\mathrm{TM}}$ flow cytometer (BD Biosciences, San Jose, CA, USA).

Hoechst staining. Cell apoptosis was determined using an apoptosis-Hoechst staining kit according to the manufacturer's instructions (Biyuntian Biotechnology Research Institute). The cells were seeded into six-well plates and cultured for $24 \mathrm{~h}$. Quercetin was then added to the cells, and the cells were incubated for a further $48 \mathrm{~h}$. The cover slips were removed from the six-well plates and the cells were washed with PBS, prior to being fixed with the fixative for $10 \mathrm{~min}$. Two further washes were performed with PBS for 3 min. Hoechst 33258 staining solution was added to the cells, which were then agitated for $5 \mathrm{~min}$ for the staining. Following staining, the cells were washed twice with PBS for 3 min, and the cover slips were sealed with a fluorescence-resistant quenching sealing solution. The cell nuclei were observed under a fluorescence microscope.

Analysis of survivin protein expression. The expression of survivin protein was analyzed using western blotting. Following treatment of the SKOV-3 cells with quercetin at different concentrations for $24 \mathrm{~h}$, the medium was changed and the cells were cultured for a further $6 \mathrm{~h}$. Different groups of cells were collected in order to extract and quantify the protein. Protein separation was performed using sodium dodecyl sulfate-polyacrylamide gel electrophoresis, and the proteins were then transferred to a nitrocellulose membrane, which was blocked for $1 \mathrm{~h}$ with $5 \%$ skimmed dry milk. The membrane was subsequently incubated overnight at $4^{\circ} \mathrm{C}$ with rabbit polyclonal anti-human survivin antibody [cat. no. ab24479, Abcam Trading (Shanghai) Co., Ltd., Shanghai, China] diluted 1:1,000 in blocking buffer, and mouse monclonal anti- $\beta$-actin antibody [cat. no. ab8226, Abcam Trading (Shanghai) Co., Ltd.] diluted 1:1,000 in blocking buffer, prior to being washed with Tris-buffered saline with Tween 20 (TBST) three times for 10 min each time. An enhanced chemiluminescence western blotting kit (Suzhou JiShi Biological Technology Co., Ltd., Suzhou, China) was used for detection.

Cell cycle analysis. The cell cycle was analyzed using FCM. Briefly, the cells in the logarithmic phase were seeded into 12 -well plates and cultured for $24 \mathrm{~h}$, followed by the addition of quercetin $(30 \mathrm{mg} / \mathrm{ml})$ and incubation for $48 \mathrm{~h}$. The cells were then digested using trypsin and after $30 \mathrm{~min}$ were centrifuged at $700 \mathrm{xg}$ for $5 \mathrm{~min}$ at $4^{\circ} \mathrm{C}$. Following centrifugation, the pelleted cells were washed with PBS, resuspended and fixed with ice-cold ethanol overnight at $4^{\circ} \mathrm{C}$. The cells were stained with PI for $1 \mathrm{~h}$ and analyzed using FCM.

Statistical analysis. Results are expressed as the mean \pm SD. Statistical analysis was conducted with a one-way analysis of variance using SPSS software (SPSS, Inc., Chicago, IL, USA). $\mathrm{P}<0.05$ was considered to indicate a statistically significant difference.

\section{Results}

Inhibitory effect of quercetin on the proliferation of SKOV-3 cells. The proliferation of human ovarian cancer SKOV-3 cells treated with quercetin at different concentrations $(0,0.12,0.23$, $0.47,0.94,1.88,3.75,7.5,15$ and $30 \mathrm{mg} / \mathrm{ml}$ ) for 24 and $48 \mathrm{~h}$, respectively, was determined by an MTT assay. As shown in Fig. 1, the growth of the SKOV-3 cells was significantly inhibited by quercetin treatment, and cell proliferation was also suppressed. Furthermore, the inhibitory effect of quercetin at the same dose on the growth of SKOV-3 cells was enhanced by an increase in the incubation time. The inhibitory rate of cell proliferation increased in a dose- and time -dependent manner. The strongest inhibitory effect on cell growth was observed following treatment with $30 \mathrm{mg} / \mathrm{ml}$ quercetin, when the inhibitory rate of cell proliferation reached its peak value (58.72\%).

Effect of quercetin on the apoptosis of SKOV-3 cells. Following the double staining of the SKOV-3 cells with Annexin V-FITC and PI, the role of quercetin in cell apoptosis was analyzed by FCM. In Fig. 2, normal cells were located within the lower left quadrant, while apoptotic cells in the early stage of apoptosis were observed within the lower right quadrant. Apoptotic cells in the late stage of apoptosis and the dead cells were located within the upper right quadrant. The total apoptosis rate was a sum of the early and late apoptosis rates. The results showed that the total apoptosis rate of the SKOV-3 cells treated with $15 \mathrm{mg} / \mathrm{ml}$ quercetin was significantly higher than that of the control cells $(33.62 \pm 1.17$ vs. $7.13 \pm 0.92 \%, \mathrm{n}=6, \mathrm{P}<0.01)$. When the cells were treated with $30 \mathrm{mg} / \mathrm{ml}$ quercetin, the total apoptosis rate was 


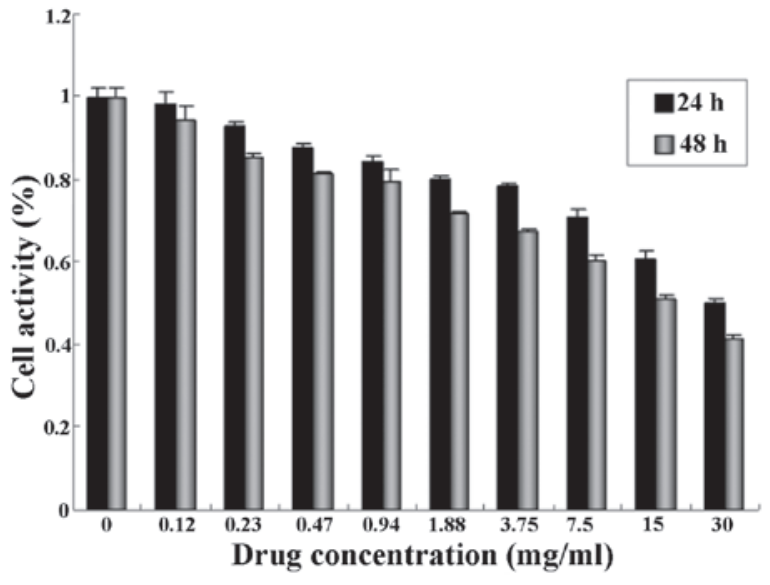

Figure 1. Effect of quercetin on the proliferation of SKOV-3 cells.

$\mathbf{A}$

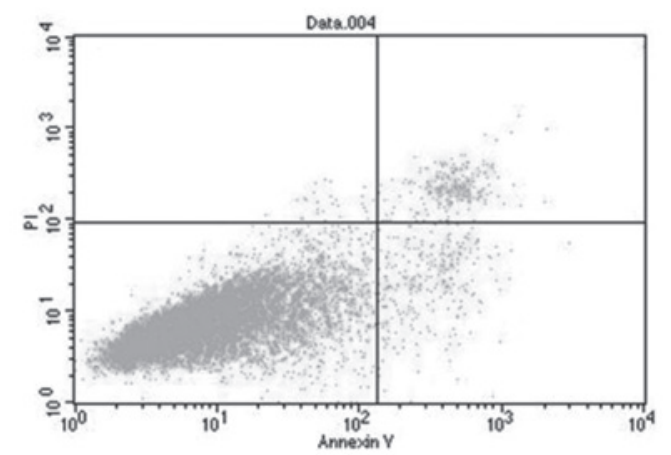

B

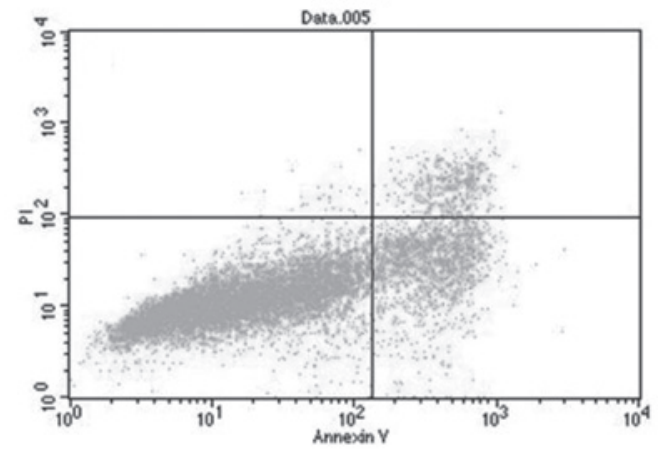

C

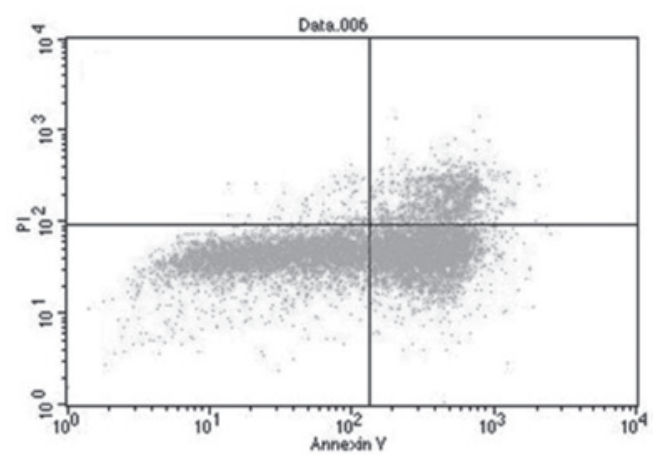

Figure 2. Effect of quercetin on the apoptosis of SKOV-3 cells. (A) $0 \mathrm{mg} / \mathrm{ml}$ quercetin group; (B) $15 \mathrm{mg} / \mathrm{ml}$ quercetin group; (C) $30 \mathrm{mg} / \mathrm{ml}$ quercetin group. PI, propdium iodide.

$69.12 \pm 2.97 \%$, which was significantly higher than that of the low-dose $(15 \mathrm{mg} / \mathrm{ml})$ quercetin group and the control $(\mathrm{n}=6$, $\mathrm{P}<0.01)$.
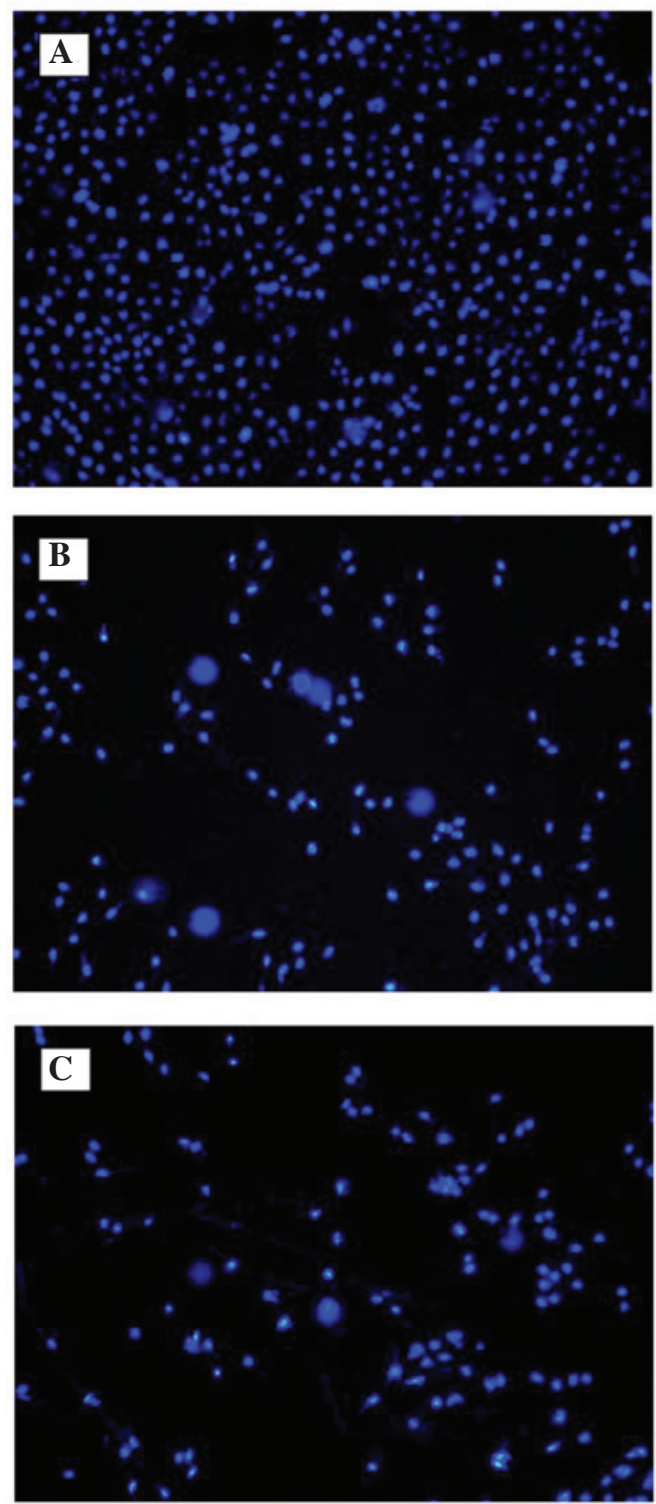

Figure 3. Apoptosis determination by Hoechst 33258 staining. (A) Control group (0 $\mathrm{mg} / \mathrm{ml}$ quercetin); (B) $15 \mathrm{mg} / \mathrm{ml}$ quercetin group; (C) $30 \mathrm{mg} / \mathrm{ml}$ quercetin group.

Apoptosis determination by Hoechst 33258 staining. Chromatin condensation occurs during tumor cell apoptosis; therefore, Hoechst 33258 staining was used in the analysis of cell apoptosis. Following the staining of the cells with Hoechst 33258, the cell nuclei were observed under a fluorescence microscope. Normal cell nuclei were evenly stained blue, while the cell nuclei of the apoptotic cells were condensed and hyperchromatic or fragmented and hyperchromatic, so the nuclei became bright white (Fig. 3). The number of apoptotic cells among the cells treated with 15 or $30 \mathrm{mg} / \mathrm{ml}$ quercetin was higher than that of the control, and the apoptosis rates in the 15 and $30 \mathrm{mg} / \mathrm{ml}$ quercetin groups were significantly higher than the rate in the control group $(\mathrm{P}<0.05)$.

Expression of survivin protein. SKOV-3 cells were treated with quercetin for $48 \mathrm{~h}$ and then survivin protein expression was analyzed using western blotting. As shown in Fig. 4, survivin protein levels were reduced following quercetin treatment. 
1

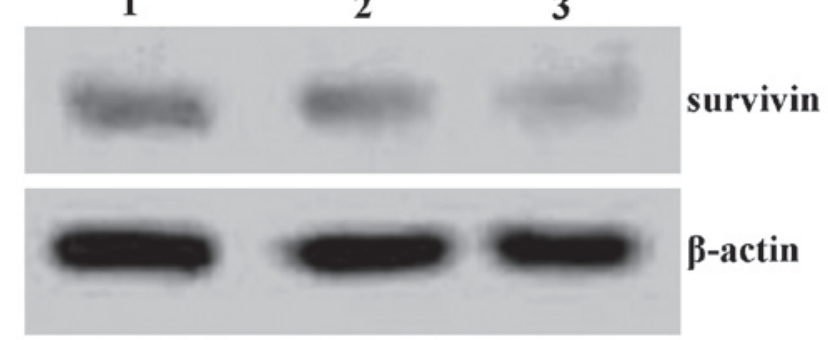

Figure 4. Expression of survivin protein in SKOV-3 cells. Lane 1, control group (0 $\mathrm{mg} / \mathrm{ml}$ quercetin); lane $2,15 \mathrm{mg} / \mathrm{ml}$ quercetin; lane $3,30 \mathrm{mg} / \mathrm{ml}$ quercetin.
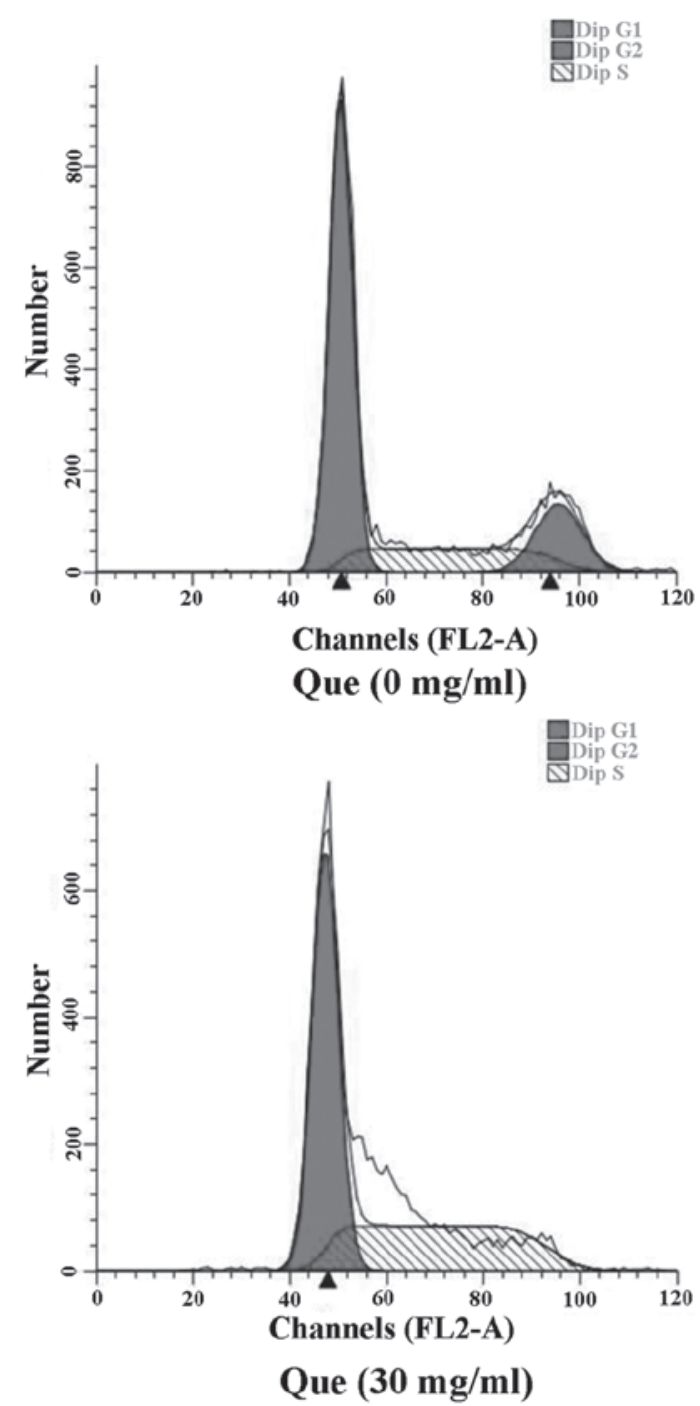

Figure 5. Effect of quercetin on the cell cycle of SKOV-3 cells.

Effect of quercetin on the cell cycle of SKOV-3 cells. The cell cycle of human ovarian cancer SKOV-3 cells treated with $30 \mathrm{mg} / \mathrm{ml}$ quercetin for $48 \mathrm{~h}$ was determined using FCM. As shown in Fig. 5, following treatment with quercetin, the percentage of cells at $G_{0} / G_{1}$ phase was significantly increased, while the percentage of cells at $\mathrm{G}_{2} / \mathrm{M}$ phase was markedly decreased compared with results for the control cells, indicating that quercetin can induce the apoptosis of
SKOV-3 cells largely by causing cell cycle arrest in the $\mathrm{G}_{1}$ phase.

\section{Discussion}

Bioflavonoids are extracted from fruits and vegetables due to their unique biological characteristics. It has been reported that flavonoids exhibit numerous biological activities, including anti-oxidative, -bacterial, -inflammatory, -viral and -cancer effects, and may play a role in cancer prevention $(9,10)$. The high incidence and mortality associated with ovarian cancer has necessitated the search for a novel effective clinical treatment. The flavonoid quercetin has been shown to be able to inhibit the proliferation and induce the apoptosis of various types of cancer cells, including colon, pancreatic, stomach, bladder and breast (11-15). In the present study, the effects of quercetin on the proliferation and apoptosis of ovarian cancer cells were investigated in order to provide an experimental basis for the clinical application of quercetin in the treatment of ovarian cancer.

In the present study, the effect of different doses of quercetin on the growth of ovarian cancer SKOV-3 cells was investigated at different time-points using an MTT assay. The results showed that quercetin inhibited ovarian cancer cell growth, and the rate of quercetin-induced cell proliferation inhibition significantly increased in a dose- and time-dependent fashion. Following the double staining of the SKOV-3 cells with Annexin V-FITC and PI, cell apoptosis was analyzed using FCM. The results showed that quercetin induced the apoptosis of ovarian cancer cells, and the cell apoptosis rate increased in a dose-dependent manner. In addition, Hoechst staining and morphological analysis demonstrated that quercetin could induce the apoptosis of ovarian cancer SKOV-3 cells. In combination, these data suggest that quercetin can not only inhibit ovarian cancer cell proliferation, but also induce the apoptosis of ovarian cancer cells. In the present study, quercetin caused a concentration- and time-dependent reduction in the viability of SKOV-3 ovarian cancer cells. The results of the present study are concordant with the findings of Yi et al (16).

Cell apoptosis plays a key role in the regulation of the proliferation of tumor cells, and the genesis and development of tumors. In the present study, the possible mechanisms by which quercetin inhibits the proliferation of ovarian cancer SKOV-3 cells were analyzed using FCM. The results showed that, following treatment with quercetin, the number of cells at $\mathrm{G}_{0} / \mathrm{G}_{1}$ phase was significantly increased, while the number of cells at $\mathrm{S}$ and $\mathrm{G}_{2} / \mathrm{M}$ phases was relatively decreased compared with the control group, indicating that quercetin can cause cell cycle arrest at the $G_{1}$ phase for ovarian cancer SKOV-3 cells, prevent cell cycle progression from $G_{1}$ to $S$ phase and induce cell apoptosis. These results suggest that cell cycle arrest is one of the important mechanisms underlying the quercetin-induced inhibition of ovarian cancer SKOV-3 cell growth, as well as quercetin-induced cell apoptosis.

In conclusion, the present study has explored the role of quercetin in the inhibition of proliferation and the induction of apoptosis in ovarian cancer SKOV-3 cells; however, the exact mechanism still requires further investigation. In this study, the effects of quercetin on the proliferation and apoptosis of ovarian cancer cells were only demonstrated through in vitro experi- 
ments. Further studies in vivo and associated clinical trials are necessary to elucidate the mechanisms by which quercetin exerts its anti-ovarian cancer properties, thus providing experimental evidence for the treatment of ovarian cancer and contributing to the development of novel quercetin-related drugs.

\section{Acknowledgements}

This study was financially supported by the Key Research Areas Subject of Xinxiang Medical University (no. ZD 2011-14), the Key Laboratory for Medical Tissue Regeneration of Henan Province (grant nos. 81301174 and 31200897 ), the Tumor and Signal Transduction Laboratory of Xinxiang Medical University (grant nos. 81272251 and 91229115) and the Scientific Research Fund of Xingxiang Medical University (no. 2014QN118).

\section{References}

1. Gilbert L, Basso O, Sampalis J, et al; DOvE Study Group: Assessment of symptomatic women for early diagnosis of ovarian cancer: results from the prospective DOvE pilot project. Lancet Oncol 13: 285-291, 2012.

2. Jelovac D and Armstrong DK: Recent progress in the diagnosis and treatment of ovarian cancer. CA Cancer J Clin 61: 183-203, 2011.

3. Drake B: Intraperitoneal chemotherapy: a reemerging approach in the treatment of ovarian cancer. J Infus Nurs 32: 314-322, 2009.

4. Slusarz A, Shenouda NS, Sakla MS, et al: Common botanical compounds inhibit the hedgehog signaling pathway in prostate cancer. Cancer Res 70: 3382-3390, 2010

5. Comalada M, Camuesco D, Sierra S, et al: In vivo quercitrin anti-inflammatory effect involves release of quercetin, which inhibits inflammation through down-regulation of the NF-kappaB pathway. Eur J Immunol 35: 584-592, 2005.
6. Ma L, Feugang JM, Konarski P, et al: Growth inhibitory effects of quercetin on bladder cancer cell. Front Biosci 11: 2275-2285, 2006.

7. Beniston RG and Campo MS: Quercetin elevates p27(Kip1) and arrests both primary and HPV16 E6/E7 transformed human keratinocytes in G1. Oncogene 22: 5504-5514, 2003.

8. Yoshida M, Yamamoto M and Nikaido T: Quercetin arrests human leukemic T-cells in late G1 phase of the cell cycle. Cancer Res 52: 6676-6681, 1992.

9. Paydar M, Wong YL, Moharam BA, et al: In vitro anti-oxidant and anti-cancer activity of methanolic extract from Sanchezia speciosa leaves. Pak J Biol Sci 16: 1212-1215, 2013.

10. Psahoulia FH, Drosopoulos KG, Doubravska L, et al: Quercetin enhances TRAIL-mediated apoptosis in colon cancer cells by inducing the accumulation of death receptors in lipid rafts. Mol Cancer Ther 6: 2591-2599, 2007.

11. Lai WW, Hsu SC, Chueh FS, et al: Quercetin inhibits migration and invasion of SAS human oral cancer cells through inhibition of NF- $\mathrm{BB}$ and matrix metalloproteinase-2/-9 signaling pathways. Anticancer Res 33: 1941-1950, 2013.

12. Bruning A: Inhibition of mTOR signaling by quercetin in cancer treatment and prevention. Anticancer Agents Med Chem 13: 1025-1031, 2013.

13. Nguyen TT, Tran E, Nguyen TH, et al: The role of activated MEK-ERK pathway in quercetin-induced growth inhibition and apoptosis in A549 lung cancer cells. Carcinogenesis 25: 647-659, 2004.

14. Hamedeyazdan S, Fathiazad F, Sharifi S and Nazemiyeh H: Antiproliferative activity of Marrubium persicum extract in the MCF-7 human breast cancer cell line. Asian Pac J Cancer Prev 13: 5843-5848, 2012.

15. Borska S, Chmielewska M, Wysocka T, et al: In vitro effect of quercetin on human gastric carcinoma: targeting cancer cells death and MDR. Food Chem Toxicol 50: 3375-3383, 2012.

16. Yi L, Zongyuan Y, Cheng G, Lingyun Z, Guilian Y and Wei G: Quercetin enhances apoptotic effect of tumor necrosis factor-related apoptosis-inducing ligand (TRAIL) in ovarian cancer cells through reactive oxygen species (ROS) mediated CCAAT enhancer-binding protein homologous protein (CHOP)-death receptor 5 pathway. Cancer Sci 105: 520-527, 2014. 